\title{
Developments in coffee biotechnology-in vitro plant propagation and crop improvement
}

\author{
Vinod Kumar • M. Madhava Naidu •
}

G. A. Ravishankar

Received: 26 November 2005/ Accepted: 26 June 2006/ Published online: 5 October 2006

(C) Springer Science+Business Media B.V. 2006

\begin{abstract}
Coffee is an important plantation crop grown in about 80 countries across the globe. In recent years, coffee attained lot of attention in the biotechnology research area. Since last three decades, there has been a steady flow of information on coffee biotechnology and now it is entering into the genomic era. Major milestones in coffee biotech research are successful in vitro manipulation and multiplication of coffee, development of gene transfer protocols and generation of transgenic coffee plants with specific traits. The isolation of genes involved in caffeine biosynthetic pathway has opened up new avenues for generating caffeine free transgenic coffee. With the initiation of international coffee genomics initiatives, the genomic research in coffee is expected to reach new dimensions. The IPR issues may play crucial role in sharing of benefits during international collaborations in near future. This review focuses
\end{abstract}

V. Kumar · G. A. Ravishankar ( $\square)$

Plant Cell Biotechnology Department, Central Food

Technological Research Institute, Mysore,

Karnataka 570020, India

e-mail: pcbt@cftri.res.in

M. M. Naidu

Plantation Products, Spices \& Flavor Technology

Department, Central Food Technological Research

Institute, Mysore, Karnataka 570020, India on the basic and applied aspects of coffee biotechnology for newer potentials.

Keywords Biotechnology $\cdot$ Coffee $\cdot$ Somatic embryos · Tissue culture $\cdot$ Micropropagation · Caffeine pathway $\cdot$ Transgenic

\section{Introduction}

Presently, coffee is cultivated on 11.6 million ha and global production is 6.3 million tons. As an agro based rural enterprise this industry is a source of direct employment in the area of cultivation and provides employment in processing and trade sections. It is highly labour-intensive industry, employing an estimated 100 million people in over 60 developing countries. World average productivity is $505 \mathrm{~kg} / \mathrm{ha}$ (Anonymous 2005).

\section{Commercial coffee}

From the commercial point of view, only two coffee species are cultivated extensively: Coffea arabica (Arabica) and Coffea canephora (Robusta). Some other species, such as Coffea liberica, Coffea dewevrei and Coffea racemosa, are only cultivated to satisfy local consumption. Coffea arabica is native to the highlands of 
south-western Ethiopia and was brought from tropical Africa and introduced into the American continent in the first decade of the 18th century. It has contributed to the economic and cultural development of the countries where it has been cultivated. Arabica coffee, grown at altitudes of $1000-2000 \mathrm{~m}$, is responsible for about $75 \%$ of commercial world coffee and for all the coffee production in Latin America (Carneiro 1997). This species is also produced in some African countries, such as Ethiopia and Kenya. The economic qualities of $C$. arabica, together with its autogamous and perennial character, have led to the development of homogeneous plantations all over the world.

Coffea canephora has a very wide geographic distribution, extending from the western to the central tropical and subtropical regions of the African continent, from Guinea and Liberia to Sudan and the Uganda forest, with a high concentration of types in the Democratic Republic of Congo (Carneiro 1997). Coffea canephora or robusta, as it is commonly called, grows at low altitudes (about $850 \mathrm{~m}$ ), and accounts for $80 \%$ of African coffee production. However, robusta has also been cultivated in American and Asian countries.

Coffee breeding by conventional methods is a long process involving several different techniques, namely, selection from wild populations followed by hybridisation and progeny evaluation, back crossing and inter-specific crosses. Unfortunately, these traditional methods of improvement are slow and it takes more than 30 years to obtain a new cultivar using any of these methods and are also expensive, thus the resulting seed production and distribution is insufficient to satisfy the needs of coffee growers. Leaf rust caused by Hemileia vastatrix $\mathrm{B}$.et. $\mathrm{Br}$ is a devastating disease of great economic significance for coffee production. Arabica coffee is very susceptible to leaf rust and this may be due to the narrow genetic base of the commercial populations, which are known to be derived from very few plants (Smith 1985). The tetraploidy of $C$. arabica versus the diploidy of all other species of Coffee prevents ready flow of genes between arabica and other species. Thus, improving arabica coffee with the specific objective of rust resistance without compromising on yield and productivity is a task of considerable dimension. Biotechnological approaches and transgenic research may be helpful in overcoming these bottlenecks and for supplementing conventional breeding programs.

The introduction of in vitro propagation techniques, with the potential to multiply genotypes of superior value at a faster rate, has proved to be a major advantage. Several methods of in vitro regeneration and propagation in coffee have already been optimised successfully, including somatic embryogenesis and scale-up of somatic embryogenesis using bioreactors, apical meristem and axillary bud culture, induction and development of adventitious buds, culture of zygotic embryos, anther/pollen culture, cell suspension culture and protoplast culture (Hatanaka et al. 1991; Neuenschwander and Baumann 1991; Sreenath et al. 1995; Madhava Naidu and Sreenath 1999; Giridhar et al. 2004a; b; c). The advances made to date in in vitro coffee techniques have allowed the manipulation of the coffee plant at cellular and molecular levels, making coffee a suitable crop for the application of biotechnological breeding programs, including genetic transformation.

Studies in coffee biotechnology have been pursued for the last three decades in various laboratories around the world and concentrated on the improvement of agronomic and processing qualities. In this communication, we intend to provide coffee researchers with information on advances made in crop improvement through biotechnology, which includes in vitro micropropagation, and genetic manipulation for desired traits.

\section{In vitro multiplication}

Conventionally, coffee is propagated from seed or by vegetative cuttings. Seed propagation is associated with inherent uncontrolled genetic variation in heterozygous cultivars, slow rates of multiplication of seed and short span of seed viability. Propagation of coffee by vegetative cuttings guarantees uniformity. Cuttings generate relatively low multiplication rates as they can only be obtained from orthotropic branches. 
Multiplication by tissue culture techniques could provide a viable alternative to these traditional methods of coffee propagation. Tissue culture methods permit the production of relatively uniform plants on a massive scale in a shorter period, and with a narrower genetic base than those under the conventional methods. Various approaches that have been considered for in vitro multiplication of coffee species are somatic embryogenesis, meristem culture, axillary bud culture and development of adventitious buds.

\section{Micropropagation}

The coffee plant presents one apical meristem and each axil leaf has 4-5 dormant orthotropic buds and two plagiotropic buds. The plagiotropic buds only start development from the 10th and 11th node. For apical meristem culture and the culture of dormant buds, both orthotropic and Plagiotropic buds, give rise to plantlets, which can be used as initial explants for coffee micropropagation. Micro-cuttings or nodal culture comprise a tissue culture approach which entails culturing nodal stem segments carrying dormant auxiliary buds, and stimulating them to develop. Since this method involves the exploitation of buds already present on the parent stock plant, it provides means of clonal multiplication. Each single segment can produce 7-9 micro-cuttings every eighty days. Most of these work was carried out during the 1980s. These aspects have been covered extensively in an earlier review (Reviewed by Carneiro 1999).

Micropropagation to mass multiply the superior coffee genotypes using apical or axillary meristem culture have been reported by a number of groups during the 1980s (Reviewed by Carneiro 1999). However, the maximum rate of multiplication obtained was nine shoots per explant (Carneiro and Ribeiro 1989). Culture of micro-cuttings in temporary immersion systems has resulted in a 6-fold increase in the multiplication rate, in comparison with micro-cuttings multiplied on solid medium (Berthouly et al. 1994; Teisson et al. 1995). The field performance of embryo-regenerated plants have been reported and found to show normal response in terms of physiology and yield. In order to validate the propagation technology of Coffea canephora Pex Fr. var. Robusta via somatic embryogenesis in liquid medium, the clonal fidelity of regenerated trees has been assessed for the first time in largescale field trials (Ducos et al. 2003). A total of 5067 trees originating from 5 to 7 -month-old embryogenic cell suspension cultures were planted in the Philippines and in Thailand for comparing with control trees derived from in vitro axillary budding. For the observed morphological traits and the yield characteristics, no significant differences were seen between the somatic seedlings and the micro-cutting derived trees (Ducos et al. 2003). However, the occurrence of some phenotypic variants difficult to visualise or somaclonal variations at the DNA level cannot be excluded. However, the initial establishment of in vitro culture is a difficult task due to the presence of large amount of phenolics.

Adventitious shoot development is an alternative method of coffee micropropagation. Shoots originating in tissues located in areas other than leaf axil or shoot tips are subjected to one phase of dedifferentiation followed by differentiation and morphogenesis (Ganesh and Sreenath 1999, Reviewed by Carneiro 1999).

\section{Somatic embryogenesis}

Plant embryogenesis represents the most definitive stages of the plant life cycle, with the overall architectural pattern of the mature organism established during a relatively short interval. Endogenous and exogenously administered hormones and explant source play a crucial role in somatic embryogenesis in genotype specific manner. Embryo to embryo multiplication i.e., secondary embryogenesis process requires a fine balance in the reprogramming of cells towards re-differentiation and maturation. Somatic embryogenesis was well documented in coffee (Staritsky 1970; Sharp et al. 1973). The callus induction was more efficient in the absence of light. During the last 35 years, a number of protocols for somatic embryogenesis have been developed for various genotypes of Coffee (Reviewed by Carneiro 1999). High frequency of 
somatic embryogenesis (HFSE) and low frequency of somatic embryogenesis (LFSE) were established from leaf sections of C. arabica cv. Bourbon (Söndahl and Sharp 1977). Dublin (1980a; b) described somatic embryogenesis in leaf segments of Arabusta. Somatic embryos and plantlets were obtained with different types of explants (Molina et al. 2002, Reviewed by Carneiro 1999). Even from coffee seed integument (perisperm) tissues of coffee, embryogenesis was successful (Sreenath et al. 1995).

The time required for embryogenesis in coffee reported by various groups range from 8 months to more than a year (Reviewed by Carneiro 1999). A number of attempts have been made to reduce the time needed for embryogenesis in coffee. Triacontanol, silver nitrate $\left(\mathrm{AgNO}_{3}\right)$, salicylic acid, thidiazuron and $2 \mathrm{iP}$ are the widely used growth regulators in coffee embryogenesis. Triacontanol incorporated at 4.55 and $11.38 \mu \mathrm{M}$ in half strength MS basal medium containing $1.1 \mu \mathrm{M}$ 6benzylaminopurine (BA) and $2.28 \mu \mathrm{M}$ indole-3acetic acid (IAA) induced direct somatic embryos in both species of $C$. arabica and $C$. canephora (Giridhar et al. 2004a). Direct somatic embryogenesis was achieved from hypocotyl explants of in vitro regenerated plantlets of $C$. arabica and C. canephora on modified MS medium containing 10-70 $\mu \mathrm{M} \mathrm{AgNO} 3$ supplemented with $1.1 \mu \mathrm{M} \mathrm{N}^{6}$ benzyladenine and $2.85 \mu \mathrm{M}$ indole-3-acetic acid (Giridhar et al. 2004b). Somatic embryogenesis in just 2-4 months was the major breakthrough in the above reports.

Indirect modes of somatic embryogenesis i.e., callus initiation followed by embryogenesis is the major reason for long duration of time required for embryogenesis. Induction of embryos directly on leaf segments would obviously reduce the time needed for production of somatic embryos. The response of $C$. arabica and C. canephora genotypes with regard to direct somatic embryogenesis was reported by Giridhar et al. (2004c). Segments of cotyledonary leaf (CXR variety), first leaf and stalk of regenerated plantlets, produced cluster of somatic embryos directly from cut portions of explants on $2 \mathrm{mg} \mathrm{l}^{-1}$ thidiazuron (TDZ) containing medium. Sub-culturing of these embryo clusters reported to produce more secondary embryos on reduced TDZ (0.01-0.2 $\left.\mathrm{mg} \mathrm{l}^{-1}\right)$ containing medium and subsequently developed into plantlets followed by rooting on MS basal medium.

Shoots of arabica and robusta coffee showed increased growth when cultured on MS medium containing $\mathrm{AgNO}_{3}$, IAA and BA (Giridhar et al. 2003). Incorporation of $\mathrm{AgNO}_{3}$ at $10-40 \mu \mathrm{M}$ concentration in the culture medium enhanced growth of both $C$. arabica and $C$. canephora coffee (Giridhar et al. 2003). According to a method reported by Giridhar et al. (2004b), it could be possible to get direct somatic embryogenesis in 2 months time. In general, 3-4 months time is required to get the yellow friable callus from leaf explants, which can be later, used for high frequency somatic embryogenesis (Van Boxtel and Berthouly 1996). Therefore, the observed effects of silver nitrate on somatic embryogenesis may further support the hypothesis that this compound acts as promoting agent for direct somatic embryogenesis and embryogenic callus formation which may be attributed to its ethylene regulation action during specific stages of Coffea embryogenesis.

Interestingly, picomolar concentrations of salicylates reported to induce cellular growth and enhance somatic embryogenesis in $C$. arabica tissue culture (Quiroz-Figueroa et al. 2001). Other than exogenous growth hormones ethylene (Hatanaka et al. 1995) and dissolved oxygen concentration (Manuel de Feria et al. 2003) known to play a crucial role in coffee somatic embryogenesis. Further work was carried out to assess the effect of different ethylene inhibitors such as cobalt chloride and salicylic acid. The results indicated that compared to other ethylene inhibitors, silver nitrate is highly efficient in eliciting secondary embryogenesis response from primary somatic embryos Table 1 contains a brief summary of reports on somatic embryogenesis from coffee.

\section{Scale up of embryos in bioreactors}

Liquid cultures are known to be highly efficient in eliciting embryogenesis response in a number of plant systems. Bioreactors play an important role in scaling up the production for commercialisation of somatic embryogenesis based plant 


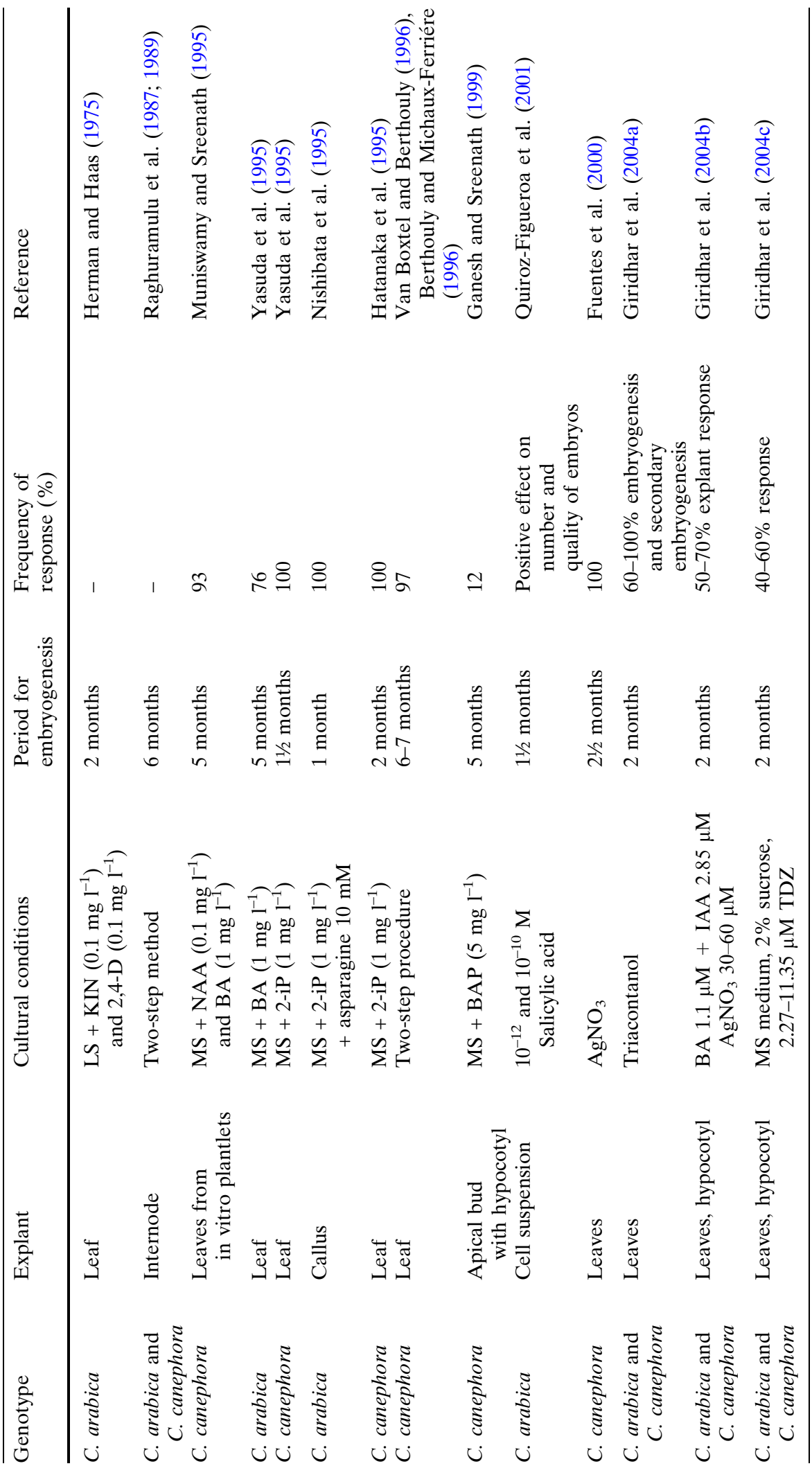


micro propagation. The induction of somatic embryogenesis of $C$. arabica in liquid medium using bioreactors was described (Zamarripa et al. 1991; Zamarripa 1993). Although some reports (Zamarripa et al. 1991; Ducos et al. 1993; Noriega and Söndahl 1993) suggested somatic embryogenesis for commercial uses, the feasibility of scale-up of somatic embryogenesis was described for the first time by Zamarripa (1993) in C. canephora and Arabusta. Extensive studies have been made in the use of conventional (Reviewed by Carneiro 1999) and temporary immersion system for Coffee somatic embryo production (reviewed by Etienne and Berthouly 2002; Albarran et al. 2005). However, till today the major hindrance in scale up is synchronisation of embryogenesis and conversion of plantlets.

\section{Temporary immersion systems}

Temporary immersion systems for coffee micropropagation have been described and grouped into four categories according to operation: tilting and rocker machines; complete immersion of plant material and renewal of the nutrient medium; partial immersion and a liquid nutrient renewal mechanism; complete immersion by pneumatic driven transfer of liquid medium and without nutrient medium renewal (Etienne et al. 2002). Using a culture system based on temporary immersion in liquid medium, 40,000 embryos were obtained per gram of callus. The importance of this system lies in the simplification of handling and 10-fold reduction of labour costs. These results were reported for nine different hybrids and reported production of about 15,000 plants (Etienne et al. 1999; 2002).

\section{Problems associated with large-scale micropropagation}

Commercialisation of large-scale somatic embryogenesis is still in infancy. The main reasons are difficulty in maintaining aseptic conditions for long duration of in vitro culture. Apart from that, maintaining synchrony in induction of embryogenesis and maturation stages is difficult in coffee. Other problems include, embryo to plant conversion rate is highly variable among different genotypes and explants.

However, direct somatic embryogenesis has several advantages over propagation by microcuttings and in vitro nodal culture. It does not have the problems of phenolic accumulation in the medium, and the contamination rates are generally very low (Muniswamy and Sreenath. 1996). Furthermore, the genetic variability is relatively low and the method permits the development of plantlets in larger numbers than is possible with the micro-cuttings method. For example, one leaf segment can produce hundreds of plantlets in a single culture cycle, whereas the micro-cutting method requires several sub-culturing cycles in order to get a comparable number of plantlets.

\section{Induction and utilisation of genetic variability}

There are many ways to produce variability in vitro and sometimes it is difficult to control these variations. Some of the well-known techniques include culture of zygotic embryos, anther and pollen culture, cell suspension culture, in vitro selection and protoplast culture. The culture of zygotic embryos allows the rescue of embryos resulting from inter-specific crosses, which abort due to endosperm incompatibility. The first contribution for this field was reported by Collona (1972) for different diploid species, namely, C. canephora, $C$. dewevrei, $C$. excelsa and C. arnoldiana. Immature embryos of San Ramon (C. arabica) cv. S73 were rescued and plant regeneration was achieved at high frequency (Raghuramulu et al. 1989). Sreenath et al. (1992) reported embryo culture for three inter-specific crosses in coffee. Coffee anthers have about 2,000-40,000 microspores and each one may give a new combination during meiosis. The first attempt to obtain coffee haploid plants was made by Sharp et al. (1973). These authors reported the induction of calli from anthers of $C$. arabica cultivars Mundo Novo and Bourbon Amarelo. Successful embryogenesis in C. arabica cv. Catuai and in different progenies of Catimor was reported after the culturing of isolated microspores and 
anthers in liquid and solid media (Carneiro 1993). Söndahl et al. (1980) for the first time reported protoplast isolation and callus proliferation from friable embryogenic callus of $C$. arabica. Protoplasts were regenerated from young leaves of hybrids of $C$. arabica and C. canephora. (Orozco and Schieder 1982). The successful isolation and culture of coffee protoplasts from embryogenic calli and suspension cells has been reported by Mamatha and Sreenath (2000). More detailed information on zygotic embryo culture, haploid culture, androgenesis and protoplast culture is available in an earlier review (Carneiro 1995).

\section{Cryopreservation of coffee germplasm}

Conservation of genetic resources of Coffee is difficult because coffee seeds loose viability during conventional seed storage. Most of the coffee germplasm are maintained in field collections, which are expensive to maintain and susceptible to natural disasters or disease. Storing Coffee seeds in genebanks would reduce costs and provide a safer conservation strategy for these important genetic resources. Though not completely tolerant of drying, embryos from most Coffea sp. studied survived water contents as low as or less than $0.20 \mathrm{~g}$ water/g dry mass (Eira et al. 2002). This relatively high tolerance of desiccation suggests that seeds and embryos can be cryopreserved if both water content and cooling and heating rates are optimised. Consistent with this hypothesis, no loss of viability was observed when Coffea arabica seeds were dried to $0.20 \mathrm{~g} / \mathrm{g}$ (in equilibrium with $75 \% \mathrm{RH}$ ) and cooled in liquid nitrogen. Successfully cryopreserved Coffea arabica seeds showed minimal viability loss after 1-year storage in liquid nitrogen (Eira et al. 2002). Some of the critical factors in cryopreservation of coffee includes optimisation of moisture content (Normah and Vengadasalam 1992; Dussert et al. 1998), cooling rate (Eira et al. 2002; Dussert et al. 1998), pre-cooling parameters (Dussert et al. 1997), tolerance to cooling (Eira et al. 1999) and physiological changes (Dussert et al. 2003) during cooling. Mycock et al. (1995) reported detailed study on cryopreservation of different genus including coffee. Embryos of Coffea sp. has been successfully conserved by cryopreservation techniques (Mari et al. 1993; Abdelnour et al. 1993; Florin et al. 1993).

\section{Caffeine in coffee}

Caffeine is one of the most widely used psychoactive substances in the world, its estimated global consumption being 120,000 tones per year. The caffeine content of green coffee bean varies among the species (Table 2). A typical cup of regular coffee contains $70-140 \mathrm{mg}$ of caffeine depending on preparation, blend and cup size (Roger and Richardson 1993).

Chemically, caffeine is a purine derivative xanthine with methyl groups attached at position 2,3 , and 7. Biosynthesis and degradation of caffeine both processes occur more rapidly in immature than mature fruit (Keller et al. 1972). Caffeine and chlorogenic acid (CGA) is known to form complex in the plant tissues. When comparing the caffeine (Campa et al. 2005a) and CGA (Campa et al. 2005b) contents in green beans of 21 Coffee species or taxa, variations in these parameters showed similar trends, with an increase in CGA content always being accompanied by an increase in caffeine content. Nevertheless, CGAs were always more abundant than caffeine, thus indicating that all the CGA was not trapped as caffeine-chlorogenate complex in the seed (Campa et al. 2005b).

\section{Caffeine biosynthetic pathway}

In coffee plants caffeine is synthesised from xanthosine via 7-methyl xanthosine, 7-methyl xanthine, and theobromine. $S$-adenosyl methionine (SAM) is the actual source of the methyl groups (Reviewed by Ashihara and Suzuki 2004). The caffeine is degraded relatively slowly and involves demethylation steps to yield theobromine and theophylline. Theophylline is catabolised to xanthine via 3-methyl xanthine. However, it is unclear whether 3-methyl xanthine and/or 7-methyl xanthine are intermediates in the conversion of theobromine to xanthine (Waller and Suzuki 
Table 2 Geographical origin and caffeine content in different Coffea sp. (Campa et al. 2005a)

\begin{tabular}{lll}
\hline Species and taxa & Geographical origin & $\begin{array}{c}\text { Bean Caffeine content } \% \\
\text { dry mass basis (dmb) }\end{array}$ \\
\hline C. brevipes & & $2.36-2.96$ \\
C. canephora & Cameroon & $1.51-3.33$ \\
C. congensis & Cote-d'Ivoire & $1.08-1.83$ \\
C. eugenioides & Congo Democratic Republic & $0.44-0.60$ \\
C. heterocalyx & Kenya & $0.86-0.99$ \\
C. humblotiana & Cameroon & $0.00-0.01$ \\
C. humilis & Comores & $1.67-2.27$ \\
C. kapakata & Cote-d'Ivoire & $1.04-1.39$ \\
C. liberica dewevrei & Angola & $0.81-1.10$ \\
C. liberica Koto & Central African Republic & $0.91-1.70$ \\
C. liberica liberica & Cameroon & $1.12-1.39$ \\
C. pseudozanguebariae & Cote-d'Ivoire & $0.00-0.00$ \\
C. racemosa & Kenya & $0.86-1.25$ \\
C. salvatrix & Tanzania & $0.01-0.06$ \\
C. pocsii & Tanzania & $1.04-1.71$ \\
C. stenophylla & Tanzania & $2.05-2.43$ \\
Coffea sp. Bakossi & Cote-d'Ivoire & $0.00-0.03$ \\
Coffea sp. Congo & Cameroon & $2.11-2.37$ \\
Coffea sp. Ngongo 2 & Congo Democratic Republic & $1.90-2.32$ \\
Coffea sp. Moloundou & Congo Democratic Republic \\
Coffea sp. Nkoumbala & Congo Democratic Republic & $0.52-0.61$ \\
\hline
\end{tabular}

1989). Simulation of caffeine biosynthesis in suspension-cultured coffee cells and the in situ existence of 7-methylxanthosine was reported (Schulthess and Baumann 1995).

The two SAM-mediated methylations of the 7-methylxanthine to theobromine and caffeine, respectively, were the first-known steps of the purine alkaloid synthesis (Fig. 1.) (Roberts and Waller 1979; Baumann et al. 1983; Waller et al. 1983). In a study conducted by Looser et al. (1974), theobromine and 7-methylxanthine were identified as precursors of caffeine. The results of mixed substrate experiments have indicated that separate enzymes catalysed the $N$-3- and $N$-1-methylations (Baumann et al. 1983). Coffea arabica cell free extracts made from callus cultures in which active biosynthesis of caffeine was occurring exhibited $N$-methyltransferase enzyme activity (Waller et al. 1983). The cell suspensions showed high activity with transfer of methyl groups from $S$-adenosyl-Lmethionine to 7-methylxanthine and to theobromine producing theobromine and caffeine, respectively. The same methyltransferase activities have later been detected in cell suspension (Baumann et al. 1983). Mazzafera et al. (1994) reported the purification of theobromine $1-N$-methyltransferase (STM), the enzyme responsible for the methylation of theobromine leading to caffeine formation in coffee. STM was purified from developing endosperms of immature fruits of C. arabica. STM is a bifunctional enzyme since it also methylated 7-methylxanthine, the immediate precursor of theobromine in the caffeine biosynthetic pathway. The $K_{\mathrm{m}}$ values obtained for theobromine and 7-methylxanthine were 0.196 and 0.496 , respectively. Gillies et al. (1995) reported improved method of purification of $N$-methyltransferases from coffee endosperm. Incorporation of $20 \%(\mathrm{v} / \mathrm{v})$ glycerol in buffers during anion-exchange chromatography resulted in $54-78 \%$ yield of $N$-methyltransferase activity and a 10-20 fold purification (Gillies et al. 1995). Analysis of a gel filtration purified preparation containing all three $N$-methyltransferase activities revealed the presence of three bands at 49, 43 and $40 \mathrm{kDa}$ (Waldhausser et al. 1997a). Maximum relative and absolute second and third $N$-methyltransferase activities coincide with leaf emergence (Waldhausser et al. 1997b). The cDNAs for 7-methylxanthine methyltransferase (MXMT or theobromine synthase) (CaMXMT, CTS1 and CTS2) were successfully cloned from coffee plants (Ogawa et al.2001; Mizuno et al. 2003a, b), although CTS1 and CaMXMT were later found to be identical. 
Fig. 1 The major route of caffeine biosynthetic pathway in coffee plants.

[1] 7-Methylxanthosine synthase (xanthosine

$N$-methyltransferase), [2] $N$-methylxanthine nucleosidase,

[3] theobromine synthase

(7-methylxanthine

$\mathrm{N}$-methyltransferase) and/or caffeine synthase

(7-methylxanthine and theobromine

$N$-methyltransferase),

[4] caffeine synthase

(7-methylxanthine and

theobromine

$N$-methyltransferase)

(Ashihara and Suzuki

2004)

Using primers designed on the basis of conserved amino acid regions of tea caffeine synthase and Arabidopsis hypothetical proteins, a particular DNA fragment was amplified from an mRNA population of coffee. Subsequently, this fragment was used as a probe, and four independent clones were isolated from a cDNA library derived from coffee young leaves. Upon expression in Escherichia coli, one of them was found to encode a protein possessing 7-methylxanthine methyltransferase activity and was designated as CaMXMT. It consists of 378 amino acids with a relative molecular mass of $42.7 \mathrm{kDa}$ and shows similarity to tea caffeine synthase $(35.8 \%)$ and salicylic acid methyltransferase (34.1\%). The bacterially expressed protein exhibited an optimal $\mathrm{pH}$ for activity ranging between 7 and 9 and methylated almost exclusively 7-methylxanthine with low activity toward paraxanthine, indicating a strict substrate specificity regarding the $3-N$ position of the purine ring. $K_{\mathrm{m}}$ values were estimated to be 50 and $12 \mu \mathrm{M}$ for 7-methylxanthine and $S$-adenosyl-L-methionine, respectively (Ogawa et al. 2001). Mizuno et al. (2003b) reported isolation of a bifunctional coffee caffeine synthase (CCS1) clone from coffee endosperm by reverse transcription-polymerase chain reaction (RT-PCR) and rapid amplification of cDNA ends technique using previously reported sequence information for theobromine synthases (CTSs). The predicted amino acid sequences of CCS1 are more than $80 \%$ identical to CTSs.

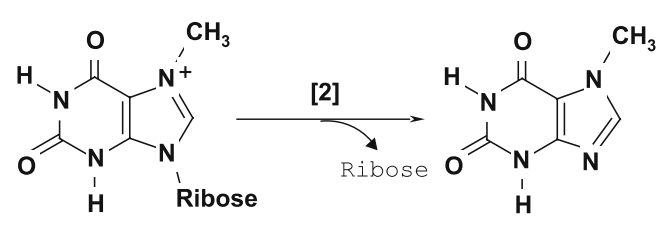

7-Methyl xanthosine

7-Methyl xanthine

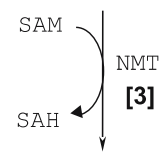

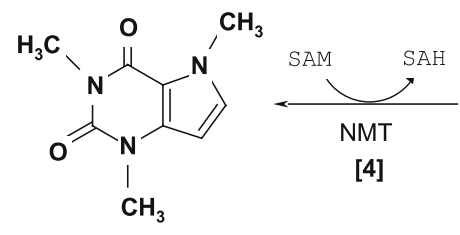

Caffeine

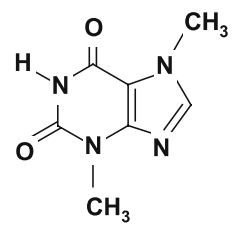

Theobromine
CCS1 has dual methylation activity (Mizuno et al. 2003b). Genes encoding 7-methylxanthine methyltransferase (MXMT) and 3,7-dimethylxanthine methyltransferase (DXMT) were isolated from immature fruits of C. arabica. Functional characterisation and in vitro reconstitution of the enzymes have been carried out. The cDNAs were named as CaMXMT2 and CaDXMT1, respectively. CaMXMT2 catalysed the formation of theobromine from 7-methylxanthine with a $K_{\mathrm{m}}$ of $251 \mu \mathrm{M}$, and CaDXMT1 catalysed the formation of caffeine from theobromine with a $K_{\mathrm{m}}$ of $1,222 \mu \mathrm{M}$ (Uefuji et al. 2003). The results suggest that, in coffee plants, caffeine is synthesised through three independent methylation steps from xanthosine (Ogawa et al. 2001; Uefuji et al. 2003).

The main biosynthesis route utilises the purine nucleotides through the steps (AMP and/or $\mathrm{GMP}) \rightarrow \mathrm{IMP} \rightarrow \mathrm{XMP} \rightarrow$ xanthosine $\rightarrow$ 7-methyl xanthosine $\rightarrow$ 7-methylxanthine $\rightarrow$ theobromine $\rightarrow$ caffeine. More detailed information on caffeine biosynthesis, the provider pathways, SAM cycle and other aspects of purine alkaloids have been discussed by Ashihara and Suzuki (Reviewed by Ashihara and Suzuki 2004). The proposed pathway of the final stage of caffeine biosynthesis in coffee is illustrated in Fig. 1.

Using gene-walking technique, the promoter for one of the $N$-methyl transferase gene has been cloned (Satyanarayana et al. 2005). The analysis 
of sequence revealed the successful $5^{\prime}$ walking in the unknown region to the extent of 745bp from the known $5^{\prime}$ end of the theobromine synthase gene. The ability of the isolated promoter to drive reporter gene expression was confirmed using a model system tobacco (Satyanarayana et al. 2004; 2005).

The cloning of the promoter for the gene involved in caffeine biosynthetic pathway opened up the possibility of studying the molecular mechanisms that regulate the production of caffeine. The promoter sequence could be used for specific down regulation of individual member of NMT gene family through transcriptional gene silencing by RNA directed DNA methylation (Mette et al. 2000).

\section{Breeding for caffeine free Coffee}

The deleterious effects of caffeine on the central nervous system are well documented and this led coffee industry to provide an artificially de-caffeinated coffee. The health conscious consumers will welcome the developments towards naturally decaffeinated coffee. Although genetic improvement using intra-specific diversity is an obvious approach, this approach seems inadequate to obtain caffeine-free coffee. Caffeine is lacking in most Malagasy species and in the East-African species C. pseudozanguebariae (Charrier and Berthaud 1975; Clifford et al. 1989). Unfortunately, caffeine-free species are low yielding and give a beverage of poor tasting quality. Psilanthus species indigenous to India were thought to be caffeine free.

However, Santa Ram et al. (2005) reported very low caffeine content $(0.05-0.07 \% \mathrm{dw})$ in $P$. bengalensis. A tetraploid Ligenioides, derived from the cross $C$. liberica $\times C$. eugenioides found to possess reduced caffeine $(1.29-1.39 \% \mathrm{dw})$ content. The seeds of Racemusta hybrids (C. racemo$s a \times C$. canephora) contain $0.82-1.43 \%$ caffeine, which was found to be much lower than that of C. canephora ( $3 \%$ ) (Santa Ram et al. 2005)

Silvarolla et al. (2004) have been able to discover a naturally decaffeinated $C$. arabica plant from Ethiopia, a species normally recognised for the high quality of its beans. They have studied 3,000 coffee trees representing 300 C. arabica accessions from Ethiopia. The study revealed that, three of these accessions are completely free of caffeine and speculated to be due to mutation in the caffeine synthase gene (Silvarolla et al. 2004). These developments clearly opened up new avenues towards breeding for low or zero caffeine coffee.

\section{Decaffeination}

The first decafffeination process was developed in Germany during 1900. Swiss water process was introduced to the American market in New York in 1979, and French water decaffeinated coffee was introduced in 1992. The use of solvent super critical $\mathrm{CO}_{2}$ for decaffeination of coffee, commercialised by HAH-GF in Germany, is based on the 1970 patent of Kurt Zosel, at Max Planck Institute, Germany. Patents have been the major sources of public information. There have been numerous process developments in decaffeination technology, the most important being solvent extraction of caffeine from pre-wetted beans. There are two basic methods for producing decaffeinated coffee using solvent, direct solvent extraction of the beans and water extraction of the beans followed by solvent extraction of the caffeine from the water extract. More detailed information is available in a review article by (Ramalakshmi and Raghavan 1999).

The Coffex Company developed the water process using water for decaffeination in 1938 in Switzerland. However, commercialisation of the process was slow; only in the late 1970s, was able to realise the commercial production, with an initial capacity of 4000 tons per year. Caffeine is transferred from steamed green beans to an intermediate from that it is recovered by thermal desorption (Hinrichsmeyer and Chammenga (1985). Some of the absorbents used are activated charcoal, molecular sieves, silica gels, bentonites, and organic ion-exchange resins. Caffeine containing green coffee extract can be decaffeinated by contact with caffeic acid, which forms an insoluble caffeine/caffeic acid, complex and can be separated (Kopsch et al. 1989). 
The adverse effects of caffeine have increased the market for decaffeinated coffee to about $10 \%$ of the coffee consumption worldwide (www.ncausa.org), despite the loss of key flavour compounds in the industrial decaffeinating process.

\section{Genetic transformation of Coffea sp.}

The success of transgenic research in Coffee has opened up new avenues for quality improvements. The early reports on coffee genetic transformation referred to co-cultivation of protoplasts with different strains of Agrobacterium tumefaciens. Barton et al. (1991) reported electroporation mediated gene delivery for the first time in protoplasts and plantlets were recovered from electroporated embryos using kanamycin as a selective marker. But now it is well known that kanamycin selection is not very efficient as hygromycin for the selection of transgenic coffee.

Ocampo and Manzanera (1991) demonstrated that $C$. arabica tissues could be infected by wild strains of Agrobacterium tumefaciens. Transgenic plants of $C$. canephora and C. arabica were obtained using genetic transformation mediated by A. rhizogenes (Spiral et al. 1993; Sugiyama et al. (1995). Transient expression of uid A gene was demonstrated by GUS histochemical assay on callus tissues derived from transformed protoplasts (Spiral et al. 1999).

Transgenic work on coffee was continued with different approaches. Some of them include, A. tumefaciens mediated genetic transformation (Grèzes et al. 1993; Madhava Naidu et al. 1998), biolistic gene delivery (van Boxtel 1994, 1995), PEG mediated direct DNA uptake (De Peña 1995), electroporation mediated gene delivery (Fernandez and Menendez 2003). We have been working on development of suitable transformation system in coffee for several years. Agrobacterium rhizogenes strain A4 harbouring plasmid pCAMBIA 1301 with an intron uid A reporter and hygromycin phosphotransferase (hpt II) marker gene was used for sonication assisted transformation of C. canephora (Kumar et al. 2003; 2004; 2006). PCR and Southern blot analysis confirmed the independent, transgenic nature of the analysed plants and indicated single and multiple locus integrations (Kumar et al. 2006). The study clearly demonstrated that Agrobacterium rhizogenes harbouring binary vectors could be used for generating transgenic coffee without hairy root phenotype and the T DNA from the Ri plasmid and the T DNA of the binary vector integrates independently in transgenic plants (Kumar et al. 2006). However, only upto 3\% transformation efficiency has been achieved.

In a recent report by Canche-Moo et al. (2006), Agrobacterium-mediated plant transformation protocol was evaluated as a fast method to obtain genetically modified $C$. canephora plantlets. Leaf explants were used as source material for A. tumefaciens-mediated transformation involving a vacuum infiltration protocol, followed by a step of somatic embryogenesis induction and a final selection of the transformed plants. Agrobacterium tumefaciens strain C58CI containing the binary vector pER10W-35SRed was used. For the first time, transformation efficiency of $33 \%$ was achieved in coffee. The authors claim to generate transgenic embryos in just two months (Canche-Moo et al. 2006). Stable transformation of $C$. canephora was obtained by particle bombardment of embryogenic tissue (Ribas et al. 2005). The somatic embryos and embryogenic tissue were bombarded with tungsten particles (M-25) carrying the plasmid pCAMBIA3301 (containing the bar and uid A genes) using a highpressure helium microprojectile device. The transgenic plants were successfully transferred to green house (Ribas et al. 2005).

\section{Transgenic coffee for down regulation of caffeine biosynthesis}

Ogita et al. (2003; 2004) have reported the simultaneous down-regulation of three distinct methylation steps of the caffeine biosynthetic pathway by RNAi. Specific sequences in the $3^{\prime}$ untranslated region (UTR) of CaMXMT1 messenger RNA were selected for construction of RNAi short and long fragments. The caffeine content of the transgenic plants reduced by up to $70 \%$, indicating that it is possible to produce coffee beans that are intrinsically deficient in caffeine (Ogita et al. 2003). In a study reported by 
Kumar et al. (2004), Agrobacterium tumefaciens mediated genetic transformation was achieved in C. canephora for silencing of $N$-methyl transferase involved in caffeine biosynthesis (Kumar et al. 2004).

\section{Transgenic coffee for resistance against leaf miner}

With regard to molecular breeding for agronomic qualities, transgenic coffea have been developed for resistance to leaf miner pest. The possible use of Bacillus thuringiensis in coffee biotechnology and the production of genetically modified coffee plants expressing the Bacillus thuringiensis cry1Ac gene for resistance to leaf miner was reported (Oliveiro et al. 1998; Leroy et al. 2000; Dufour et al. 2000). Perthuis et al. (2005) reported a field trial of transgenic clones of C. canephora transformed for resistance to the Lepidopteran coffee leaf miner Leucoptera coffeella was installed in French Guiana. Fiftyeight transformed clones produced by transformation of the $C$. canephora were planted. They were harboring the $\mathrm{pEF} 1 \alpha$ constitutive promoter of Arabidopsis thaliana controlling either the Bacillus thuringiensis native gene for the cry1Ac insecticidal protein (eight clones) or a synthetic cry1Ac gene (53 clones). Over a 4-year period after plantation, a majority of the independent transformed clones harboring the synthetic gene displayed resistance against $L$. coffeella when compared to controls.

\section{GM coffee}

So far, no GM coffee has hit the market. However, GM coffee with desired traits would come to the market. Since first commercialisation in 1996, GM crop areas have grown at rapid rates, making this one of the most rapidly adopted technologies in agriculture. Worldwide, strict regulatory frameworks are in place in many countries to ensure that all candidate GM crops are evaluated according to the latest standards of scientific knowledge for impacts on human health, animal health, and the environment be- fore authorisations for marketing are granted. The safety assessment is extremely rigorous and varies slightly from country to country (Jaffe 2004). Assessments of the GM crops currently on the market have uncovered no adverse health or environmental effects. Also, there have been no validated adverse findings during their consumption over the last 8 years (UK GM Science Review Panel 2003; 2004). Labelling the product is very essential to give freedom to the consumer on their preference towards GM or non-GM coffee. However, there is no doubt that a systematic scientific evaluation and safety assessments of GM coffee is required before releasing it to the market. This has to be followed for every new trait, within the context of a sound international broadly harmonised legislative framework.

\section{IPR Issues}

Since coffee biotechnology has tremendous application in the pre-harvest and post harvest application, protection of intellectual property rights has gained importance. Selected patents in the area of coffee biotechnology has been compiled and presented in Table 3 . These studies have bearing in the future applications of the technology for both basic and applied research. The search for value addition and improvement is bound to continue in view of the fact that coffee could continue to be an important cash crop of the world. With the initiation of international coffee genomics initiatives, it is expected that, a large number of scientific data in terms of DNA sequence, clones, gene constructs, protocols are expected to come into picture. In this case it is essential to draw a framework on sharing and distribution of materials coming under the IPR issue.

\section{Near future of coffee biotechnology}

Coffee biotechnology sector is going to take quantum leap in near future. International coffee genomics initiatives have been started with the intention of venturing into cutting edge research 
in the area of coffee biotechnology. Major objectives would be to obtain a large number of EST and genomic sequence data for functional genomic studies. The major focus would be on development of pest and disease resistant coffee, improved processing characteristics, more work on transgenics and development of marker less transformation protocols.

\section{Conclusion}

Biotechnology offers new ideas and techniques that can be applied in agriculture. It uses the conceptual framework and the technical approaches of molecular biology to develop commercial processes and products. Plant breeding has been benefited by the introduction of genetic engineering techniques, based on the knowledge of gene structure and function. Advances in cellular, developmental and molecular genetics, combined with traditional breeding, can target and achieve improvements in specific agronomic, processing and quality traits. The high performance already achieved in in vitro coffee plant regeneration systems constitutes an important breakthrough in various in vitro manipulation and regeneration processes.

Genetic transformation methods, such as direct DNA uptake, gene bombardment and mediation by Agrobacterium sp., vacuum infiltration have been shown to be reliable techniques for coffee. These facts allow coffee breeders to advance with projects aimed at developing plants resistant to the pests and diseases of coffee, plants resistant to herbicides and to other specific characteristics, particularly cold resistance, regulation of chlorogenic acid synthesis and plants which overproduce the amino acid contents involved in coffee flavour (cysteine and methionine). The improvements made in gene silencing techniques made revolutionary advancements in molecular breeding programmes. The best example is down regulation of caffeine pathway and this would be a model study for future developments towards molecular breeding for improved processing characteristics of coffee. The public concerns over marker genes in GM coffee would probably drive the researchers to think in those directions of development of marker 
free transgenic plants of coffee harbouring silencing constructs containing coffee gene fragments driven by the coffee promoters.

Acknowledgements Authors are thankful to Dr. V. Prakash, Director CFTRI, Mysore for his keen interest. VK is grateful to CSIR, New Delhi for the award of Research Fellowship. The authors are thankful to Department of Biotechnology, Government of India, for the financial assistance.

\section{References}

Abdelnour A, Engelmann F, Hibjan C et al (1993) Zygotic and somatic embryo cryopreservation in coffee (Coffea arabica, C. canephora and Arabusta). In: Proceedings of 15th colloquium of international coffee science association (ASIC), Montpellier, France

Albarran J, Bertrand B, Lartaud M et al (2005) Cycle characteristics in a temperory immersion bioreactor affect regeneration, morphology, water and mineral status of coffee (Coffea arabica) somatic embryos. Plant Cell Tiss Org Cult 81:27-36

Anonymous (2005) Globe scan, Indian Coffee, June

Ashihara H, Suzuki T (2004) Distribution and biosynthesis of caffeine in plants. Front Biosci 9:1864-1876

Barton CR, Adams TL, Zorowitz MA (1991) Stable transformation of foreign DNA into Coffea arabica plants. In: Proceed. 14th international scientific colloquium on coffee, ASIC San Fransisco, pp 460-464

Baumann TW, Koets R, Morath P (1983) N-methyltransferase activities in suspension cultures of Coffea arabica L. Plant Cell Rep 2:33-35

Berthouly M, Alvarad D, Carrasco C, Teisson C (1994) In vitro micropropagation of coffee $\mathrm{sp}$. by temporary immersion. In: Abstracts 8th international congress of plant tissue and cell culture, Florence, Italy, p 162

Berthouly M, Michaux-Ferriere N (1996) High frequency somatic embryogenesis in Coffea canephora-induction conditions and histological evolution. Plant Cell Tiss Org Cult 44:169-176

Campa C, Doulbeau S, Dussert S, Hamon S, Noirot M (2005a) Diversity in bean caffeine content among wild Coffea species: evidence of a discontinuous distribution. Food Chem 91:633-637

Campa C, Doulbeau S, Dussert S, Hamon S, Noirot M (2005b) Qualitative relationship between caffeine and chlorogenic acid contents among wild Coffea species. Food Chem 93:135-139

Canche-Moo RLR, Ku-Gonzalez A, Burgeff C, LoyolaVargas VM, Rodríguez-Zapata LC, Castaño E (2006) Genetic transformation of Coffea canephora by vacuum infiltration. Plant Cell Tiss Org Cult. DOI: 10.1007/s11240-005-9036-4

Carneiro MF (1993) Induction of double haploids via anther or isolated microspores culture. In: Proceedings of 15th colloquium of international coffee science association (ASIC), vol I, Montpellier, France, p 133
Carneiro MF (1995) Androgenesis in different progenies of Catimor. In: Abstracts of the 16th colloquium of coffee science association (ASIC), Kyoto, Japan. AP7

Carneiro MF (1997) Coffee biotechnology and its applications in genetic transformation. Euphytica 96:167172

Carneiro MF (1999) Advances in coffee biotechnology-review. Ag Biotechnet, vol 1, ABN 006, pp 1-14. Web source: http://www.agbiotecnet.com/reviews/Jan99/ HTML/Carneiro.htm)

Carneiro MF, Ribeiro TMO (1989) In vitro meristem culture and plant regeneration in some genotypes of Coffea arabica. Brot Genét 85:127-138

Charrier A, Berthaud J (1975) Variation de la teneur en caffeine dans le genre Coffea. Café Cacao Thé 19:251264

Clifford MN, Williams T, Bridson D (1989) Chlorogenic acids and caffeine as possible taxonomic criteria in Coffea and Psilanthus. Phytochemistry 28:829-838

Collona JP (1972) Contribution à l'étude de la culture in vitro d'embryons de caféiers. Action de la cafféine. Café cacao Thé 16(3):193-203

De Peña M (1995) Development of a stable transformation procedures for the protoplasts of Coffea arabica cv. Colombia. Doctoral thesis. University of Purdue, p 75

Dublin P (1980a) Multiplication végétative in vitro de l' Arabusta. Café Cacao Thé 24:281-290

Dublin P (1980b) Induction de bourgeons néoformés et embryogenèse somatique. Deux voies de multiplication végétative in vitro des caféiers cultivées. Café Cacao Thé 24:121-130

Ducos JP, Zamarripa A, Eskes AB, Petiard V (1993) Production of somatic embryos of coffee in a bioreactor. In: Proceedings of 15 th colloquium of international coffee science association (ASIC), Montpellier, France, pp 89-96

Ducos JP, Alenton R, Reano JF, Kanchanomai C, Deshayes A, Pétiard V (2003) Agronomic performance of Coffea canephora $\mathrm{P}$. trees derived from large-scale somatic embryo production in liquid medium. Euphytica 131:215-223

Dufour M, Leroy T, Carasco-Lacombe C et al (2000) Coffee (Coffea sp.) genetic transformation for insect resistance. In: Sera T, Soccol CCR, Pandey A, Roussos S (eds) Coffee biotechnology and quality. Kluwer, Dordrecht (NLD), pp 209-217

Dussert S, Chabrillange N, Engelmann F et al (1997) Cryopreservation of coffee (Coffea arabica L.) seeds: importance of precooling temperature. Cryo-Lett 18:269-276

Dussert S, Chabrillange N, Engelmann F et al (1998) Cryopreservation of seeds of four coffee species (Coffea arabica, C. costatifructa, C. racemosa and C. sessiliflora): importance of water content and cooling rate. Seed Sci Res 8:9-15

Dussert S, Chabrillange N, Jean-Luc M et al (2003) Basis of coffee seed sensitivity to liquid nitrogen exposure: oxidative stress or imbibitional damage? Physiol Plant 119(4):534-539 
Eira MTS, Walters C, Caldas LS et al (1999) Tolerance of Coffea sp. seeds to desiccation and low temperature. Revista Brasileira de Fisiologia Vegetal 11:97-105

Eira MTS, Walters C, Reis RB et al (2002) Conservation of genetic resources of coffee using cryopresvation. In: Seventh international workshop on seed biology, May 11-19, 2002, Salamanca, Spain

Etienne BD, Berthouly M (2002) Temporary immersion systems in plant micropropagation. Plant Cell Tiss Org Cult 69(3):215-231

Etienne BD, Bertrand B, Schlönvoigt A et al (2002) The morphological variability within a population of coffee somatic embryos produced in a bioreactor affects the regeneration and the development of plants in the nursery. Plant Cell Tiss Org Cult 68(2):153-162

Etienne BD, Bertrand B, Vasquez N et al (1999) Direct sowing of Coffea arabica somatic embryos mass-produced in a bioreactor and regeneration of plants. Plant Cell Rep 19:111-117

Fernandez R, Menendez A (2003) Transient gene expression in secondary somatic embryos from coffee tissues electroporated with the genes GUS and BAR. Electronic J Biotechnol 6:29-38

Florin B, Tesserea H Pétiard V (1993) Conservation à long terme des ressources génétiques de caféier par cryoconservation d'embryons zygotiques et somatiques et de cultures embryogènes. In: Proceedings of 15th colloquium of international coffee science association (ASIC), Montpellier, France

Fuentes SRL, Calheiros MBP, Manetti-Filho J et al (2000) The effects of silver nitrate and different carbohydrate sources on somatic embryogenesis in Coffea canephora. Plant Cell Tiss Org Cult 60:5-13

Ganesh SD, Sreenath HL (1999) Embryo culture in coffee: technique and applications. Indian Coffee 4:7-9

Gillies FM, Jenkins GI, Ashihara H et al (1995) In vitro biosynthesis of caffeine: the stability of $N$-methyltransferase activity in cell-free preparations from liquid endosperm of Coffea arabica. In: Proceed. 16th international scientific colloquium on coffee, ASIC, Kyoto, pp 599-605

Giridhar P, Indu EP, Ravishankar GA et al (2004a) Influence of Triacontanol on somatic embryogenesis in Coffea arabica L. and Coffea canephora P. ex. Fr. In Vitro Cell Dev Biol Plant 40:200-203

Giridhar P, Indu EP, Vijayaramu D, et al (2003) Effect of silver nitrate on in vitro shoot growth of coffee. Trop Sci 43:144-146

Giridhar P, Indu EP, Vinod K et al (2004b) Direct somatic embryogenesis from Coffea arabica L. and Coffea canephora P. Ex. Fr. under the influence of ethylene action inhibitor-silver nitrate. Acta Physiol Plant 26:299-305

Giridhar P, Vinod K, Indu EP et al (2004c) Thidiazuron induced somatic embryogenesis in Coffea arabica L. and Coffea canephora P ex Fr. Acta Bot Croat 63:25-33

Grezes J, Thomasset B, Thomas D (1993) Coffea arabica protoplast culture: transformation assays. In: Proceedings of 15 th colloquium of international coffee science association (ASIC), Montpellier France, pp 745-747
Hatanaka T, Arakawa O, Yasuda T, et al (1991) Effect of plant growth regulators on somatic embryogenesis in leaf cultures of Coffea canephora. Plant Cell Rep 10:179-182

Hatanaka T, Azuma T, Uchida N et al (1995) Effect of plant hormones on somatic embryogenesis of Coffea canephora. In: Proceed. 16th international scientific conference on coffee science, Kyoto, pp 790-797

Hermann FRP, Hass GJ (1975) Clonal propagation of Coffea arabica L. from callus culture. Hort Sci 10:588589

Hinrichsmeyer GPK, Chammenga HK (1985) Characterization of technical adsorbents for decaffeination process. ASIC 11th international colloquium on coffee, pp 369-380

Jaffe G (2004) Regulating transgenic crops: a comparative analysis of different regulatory processes. Transgen Res 13:5-19

Keller H, Wanner H, Baumann TW (1972) Caffeine synthesis in fruits and tissue culture of Coffea arabica. Planta 108:338-350

Kopsch R, Lutz H, Goesswein CF (1989) Process for separation and recovery of caffeine from raw coffee and production of decaffeinated coffee, German federal Republic Patent application, DE 3806 372 A1

Kumar V, Sathyanarayana KV, Indu EP et al (2003) Stable transformation and direct regeneration in Coffea canephora by Agrobacterium rhizogenes mediated transformation. Proceedings of 10th congress of federation of Asian and Ocianian Biochemists and Molecular Biologists, p 10

Kumar V, Sathyanarayana KV, Indu EP et al (2004). Post transcriptional gene silencing for down regulating caffeine biosynthesis in Coffea canephora P ex Fr. In: Proceedings of 20th international conference on coffee science (ASIC-2004), Oct 11-15, Bangalore, India, pp 769-774

Kumar V, Satyanarayana KV, Indu EP et al (2006) Stable transformation and direct regeneration in Coffea canephora by Agrobacterium rhizogenes mediated transformation without hairy root phenotype. Plant Cell Rep 25:214-222

Leroy T, Henry AM, Royer M et al (2000) Genetically modified coffee plants expressing the Bacillus thuringiensis cry1Ac gene for resistance to leaf miner. Plant Cell Rep 19:382-389

Looser E, Baumann TW, Wanner H (1974) The biosynthesis of caffeine in the coffee plant. Phytochemistry 13:2515-2518

Madhava Naidu M, Sreenath HL (1999) In vitro culture of zygotic embryos for germplasm preservation. Plant Cell Tiss Org Cult 55:227-230

Madhava Naidu M, Veluthambi K, Srinivasan CS et al (1998) Agrobacterium mediated transformation in Coffea canephora. Dev Plant Crops Res 46-50

Mamatha HN, Sreenath (2000) Isolation and culture of coffee protoplasts from embryogenic calli suspension cells. In: International conference on plantation crops 12-15 Dec 2000 at Hyderabad, India 
Manuel de Feria, Elio Jiménez, Raúl Barbón et al (2003) Effect of dissolved oxygen concentration on differentiation of somatic embryos of Coffea arabica cv. Catimor 9722. Plant Cell Tiss Org Cult 72(1):1-6

Mari S, Englemann F, Chabrillange N et al (1993) Cryopreservation of apices of Coffea racemosa and Coffea sessilifora using the encapsulation/dehydration technique. In: Proceedings of 15 th colloquium of international coffee science association (ASIC), Montpellier, France

Mazzafera P, Wingsle G, Olsson O et al (1994) S-adenosylL-methionine: theobromine $1-N$-methyltransferase, an enzyme catalyzing the synthesis of caffeine in coffee. Phytochemistry 37:1577-1584

Mette MF, Aufsatz W, van der Winden J et al (2000) Transcriptional gene silencing and promoter methylation triggered by double standard RNA. EMBO J 19:5194-5201

Mizuno K, Kato M, Irino F et al (2003a) The first committed step reaction of caffeine biosynthesis: 7-methylxanthosine synthase is closely homologous to caffeine synthases in coffee (Coffea arabica L.). FEBS Lett 547(1-3):56-60

Mizuno K, Okuda A, Kato M, et al (2003b) Isolation of a new dual-functional caffeine synthase gene encoding an enzyme for the conversion of 7-methylxanthine to caffeine from coffee (Coffea arabica L.). FEBS Lett 534(1-3):75-81

Molina DM, María E, Aponte et al (2002) The effect of genotype and explant age on somatic embryogenesis of coffee. Plant Cell Tiss Org Cult 71(2):117-123

Muniswamy B, Sreenath HL (1995) High frequency somatic embryogenesis form cultured leaf explants of Coffea canephora on a single medium. J Coffee Res 25(2):98-101

Muniswamy B, Sreenath HL (1996) Effect of kanamycin on callus induction and somatic embryogenesis in cultured leaf tissues on Coffea canephora Pierre (Robusta). J Coffee Res 26(1):44-51

Mycock DJ, Wesley-Smith J, Berjak P (1995) Cryopreservation of somatic embryos of four species with and without cryoprotectant pre-treatment. Annal Bot 75:331-336

Neuenschwander B, Baumann T (1991) A novel type of somatic embryogenesis in Coffea arabica. Plant Cell Rep 10:608-612

Nishibata T, Azuma T, Uchida N et al (1995) Amino acids on somatic embryogeneis in Coffea arabica. In: Proceed. 16th international scientific colloquium on coffee, ASIC, Kyoto, pp 839-844

Noriega C, Söndahl MR (1993) Arabica coffee micropropagation through somatic embryogenesis via bioreactors. In: Proceed. 15th international scientific colloquium on coffee, ASIC, Montpellier, France, pp $73-81$

Normah MN, Vengadasalam M (1992) Effects of moisture content on cryopreservation of Coffea and Vigna seeds and embryos. Cryo Lett 13(3):199-208

Ocampo CA, Manzanera LM (1991) Advances in genetic manipulation of the coffee plant. In: Proceed. 14th international scientific colloquium on coffee, ASIC, San Francisco, USA, pp 378-382

Ogawa M, Herai Y, Koizumi N et al (2001) 7-Methylxanthine methyltransferase of coffee plants. J Biol Chem 276:8213-8218

Ogita S, Uefuji H, Morimoto M et al (2004) Application of RNAi to confirm theobromine as the major intermediate for caffeine biosynthesis in coffee plants with potential for construction of decaffeinated varieties. Plant Mol Biol 54:931-941

Ogita S, Uefuji H, Yamaguchi Y et al (2003) RNA interference: producing decaffeinated coffee plants. Nature 423:823

Oliveiro GF, Peter D, Marnix P et al (1998) Susceptibility of the Coffee Leaf Miner (Perileucoptera spp.) to Bacillus thuringensis O-endotoxins: a model for transgenic perennial crops resistant to endocarpic insects. Curr Microbiol 36:175-179

Orozco FJ, Schieder D (1982) Eislamento y cultivo de protoplastos a partir de hojas de café. Cenicafe 33:129-136

Perthuis B, Pradon JL, Montagnon C et al (2005) Stable resistance against the leaf miner Leucoptera coffeella expressed by genetically transformed Coffea canephora in a pluriannual field experiment in French Guiana. Euphytica 144(3):321-329

Quiroz-Figueroa FR, Fuentes-Cerda CFJ, Rojas-Herrera $R$ et al (2002) Histological studies on the developmental stages and differentiation of two different somatic embryogenesis systems of Coffea arabica. Plant Cell Rep 20:1141-1149

Quiroz-Figueroa M, Méndez-Zeel A, Larqué-Saavedra VM et al (2001) Picomolar concentrations of salicylates induce cellular growth and enhance somatic embryogenesis in Coffea arabica tissue culture. Plant Cell Rep 20:679-684

Raghuramulu Y, Purushotham K, Sreenivasan MS et al (1987) In vitro regeneration of coffee plantlets in India (Brief note). J Coffee Res 17(2):57-64

Raghuramulu Y, Sreenivasan MS, Ramaiah PK (1989) Regeneration of coffee plantlets through tissue culture techniques in India. J Coffee Res 19(1):30-38

Ramalakshmi K, Raghavan B (1999) Caffeine in Coffee: its removal. Why and How? Crit Rev Food Sci Nutr 39(5):441-456

Ribas AF, Kobayashi AK, Pereira LFP Vieira LGE (2005) Genetic transformation of Coffea canephora by particle bombardment. Biol Plant 49(4):493-497

Roberts MF, Waller GR (1979) $N$-methyltransferases and 7-methyl- $N^{9}$-nucleoside hydrolase activity in Coffea arabica and the biosynthesis of caffeine. Phytochemistry 18:451-455

Roger PJ, Richardson NJ (1993) Why do we like drinks that contains caffeine. Trends Food Sci Technol 4(4):108-111

Santa Ram A, Indu EP, Chandrashekar A et al (2005) Identification of low caffeine coffees in some interspecific hybrids and their progenies. J Plantation Crops 33(2):90-94

Satyanarayana KV, Kumar V, Chandrashekar A et al (2004) Cloning and characterization of promoter for $\mathrm{N}$-methyl transferase gene from coffee. In: Proceedings of 20th 
international conference on coffee science (ASIC2004), Oct 11-15, Bangalore, India, pp 783-786

Satyanarayana KV, Vinod Kumar, Chandrashekar A, Ravishankar GA (2005) Isolation of promoter for $\mathrm{N}$-methyltransferase gene associated with caffeine biosynthesis in Coffea canephora. J Biotechnol 119:20-25

Schulthess BH, Baumann TW (1995) Are xanthosine and 7 methylxanthosine caffeine precuasal? Phytochemistry 39(6):1363-1370

Sharp WR, Caldas LS, Crocomo OJ et al (1973) Production of Coffea arabica callus of three ploidy levels and subsequent morphogenesis. Phyton 31:67-74

Silvarolla MB, Mazzafera P, Fazuoli LC (2004) A naturally decaffeinated arabica coffee. Nature 429:826

Smith RF (1985) A history of coffee. In: Clifford MN, Willson KC (eds) Coffee-botany, biochemistry and production of beans and beverage. The avi publishing company, Inc., Westport, Connecticut, pp 1-12

Söndahl MR, Chapman MS, Sharp NR (1980) Protoplast liberation, cell wall construction and callus proliferation in Coffea arabica L. callus tissues. Turrialba 30:161-165

Söndahl MR, Sharp W (1977) High frequency induction of somatic embryos in cultured leaf explants of Coffea arabica L. Z. Pflanzen 81:395-408

Spiral J, Leroy T, Paillard M et al (1999) Transgenic Coffee (Coffea species). In: Biotechnology in agriculture and forestry, vol 44 Transgenic trees (ed. YPS Bajaj), Springer-Verlag, Berlin Heidelberg, pp 55-76

Spiral J, Thierry C, Paillard M et al (1993) Obtention de plantules de Coffea canephora Pierre (Robusta) transformés par Agrobacterium rhizogenes. Comptes Rendus d'Académie des Sciences Series 3(316):1-6

Sreenath HL, Muniswamy B, Naidu MM et al (1992) Embryo culture of three interspecific crosses in coffee. J Plant Crops 20(Suppl.):243-247

Sreenath HL, Shantha HM, Harinath Babu K et al (1995) Somatic embryogenesis from integument (perisperm) cultures of coffee. Plant Cell Rep 14:670-673

Staritsky G (1970) Embryoid formation in callus cultures of coffee. Acta Bot Neerlandica 19:509-514

Sugiyama M, Matsuoka C, Takagi T (1995) Transformation of coffee with Agrobacterium rhizogenes. In: Proceed. 16th international scientific colloquium on coffee, ASIC, Paris, France, pp 853-859

Teisson C, Alvarad D, Berthouly M et al (1995) Culture in vitro par immersion temporaire: un nouveau récipient. Plantations Recherche Dév 2(5):29-31

Uefuji H, Ogita S, Yamaguchi Y et al (2003) Molecular cloning and functional characterization of three distinct $N$-methyltransferases involved in the caffeine biosynthetic pathway in coffee plants. Plant Physiol 132:372-380

UK GM Science Review Panel (2003) GM science review, first report. An open review of the science relevant to
GM crops and food based on interests and concerns of the public. http://www.gmsciencedebate.org.uk/report/default. htm\#Wrst

UK GM Science Review Panel (2004) GM science review, second report. An open review of the science relevant to GM crops and food based on interests and concerns of the public. http://www.gmsciencedebate. org.uk/ report/default. htm\#second

van Boxtel J, Berthouly M (1996) High frequency somatic embryogenesis from coffee leaves: factors influencing embryogenesis, and subsequent proliferation and regeneration in liquid medium. Plant Cell Tiss Org Cult 44:7-17

van Boxtel J, Berthouly M, Carasco C et al (1995). Transient expression of beta-glucuronidase following biolistic delivery of foreign DNA into coffee. Plant Cell Rep 14(12):748-752

van Boxtel J (1994) Studies on genetic transformation of coffee by using electroporation and biolistic method. Abstract available from Internet: http://www.agralin.nl/wda/abstracts/ab1880.html

Waldhausser SSM, Gillies FM, Crozier A et al (1997b) Separation of the N-7 methyltransferase, the key enzyme in caffeine biosynthesis. Phytochemistry 45:1407-1414

Waldhausser SSM, Kretschmar JA, Baumann TW (1997a) $\mathrm{N}$-methyltransferase activities in caffeine biosynthesis: biochemical characterization and time course during leaf development of Coffea arabica. Phytochemistry 44:853-859

Waller GR, MacVean CD, Suzuki T (1983) High production of caffeine and related enzyme activities in callus cultures of Coffea arabica L. Plant Cell Rep 2:109-112

Waller GR, Suzuki T (1989) Caffeine metabolism by Coffea arabica L. fruit, ASIC 13th international colloquium on coffee, Paipa, Colombia, pp 351-361

Yasuda T, Tahara M, Hatanaka T, Nishibata T, Yamaguchi T (1995) Clonal propagation through somatic embryogenesis of coffee species. In: Proceed. 16th international scientific colloquium on coffee. ASIC, Kyoto, pp 537-541

Zamarripa A (1993) Étude et dévelopment de l'embryogenèse en millieu liquid du caféier (Coffea canephora P., Coffea arabica L. et l'hybrid Arabusta). Thèse de doctorat, École National Supérieure Agronomique, Rennes, France, p 191

Zamarripa A, Ducos JP, Tessereau H et al (1991) Developpment d'un procède de multiplication en masse du caféier par embryogènese somatique au millieu liquide. In: Proceedings of the 14th colloquium of international coffee science association (ASIC), San Francisco, USA, pp 392-402 